\title{
OPENGEOEDU - A MASSIVE OPEN ONLINE COURSE ON USING OPEN GEODATA
}

\author{
R. Bill ${ }^{1}$, A. Lorenzen-Zabel ${ }^{1}$, M. Hinz ${ }^{1}$, J. Kalcher ${ }^{2}$, A. Pfeiffer ${ }^{2}$, A. Brosowski², H. Aberle ${ }^{3}$, M. Hovenbitzer ${ }^{3}$, G. Meinel ${ }^{4}$, S. \\ Sikder $^{4}$, H. Herold ${ }^{4}$,
}

\begin{abstract}
${ }^{1}$ Rostock University, Chair for Geodesy and Geoinformatics, Justus-von-Liebig-Weg 6, D-18059 Rostock, \{ralf.bill, axel.lorenzenzabel, matthias.hinz\}@ uni-rostock.de

${ }^{2}$ German Biomass Research Centre gGmbH (DBFZ), Department of Bioenergy Systems, Torgauer Straße 116, 04347 Leipzig, \{andre.brosowski, jasmin.kalcher, alexandra.pfeiffer\}@dbfz.de

${ }^{3}$ Federal Agency for Cartography and Geodesy (BKG), Remote Sensing and Development, Richard-Strauss-Allee 11, 60598 Frankfurt am Main, \{michael.hovenbitzer, henning.aberle\} @ bkg.bund.de

${ }^{4}$ Leibniz Institute of Ecological Urban and Regional Development (IÖR), Research Area Monitoring of Settlement and Open Space, Weberplatz 1, 01217 Dresden, \{g.meinel, s.sikder, h.herold\}@ioer.de
\end{abstract}

\section{Commission V, WG V/4}

KEY WORDS: Online course, Open Geodata, OpenGeoEdu, Case studies, Data portal

\section{ABSTRACT:}

This article presents the concept, implementation and results of the project "OpenGeoEdu", an open and web-based educational resource on Remote Sensing and GIS. OpenGeoEdu is focused on the use of open geodata in spatially oriented study courses. Teachers and students in the German-speaking countries are to be offered an open learning environment hoping to increase the motivation of students and researchers by dealing with current societal relevant issues. OpenGeoEdu is available at www.opengeoedu.de, has been offered as a MOOC since October 2018 and is being continuously expanded and developed. In addition, an umbrella portal of the portals on open geodata is available to quickly get an overview of the data offered. Four partners from universities, non-university research institutions as well as federal research authorities with R\&D tasks are collaborating in this project offering case studies for teaching and education based on their experiences in a wide range of spatial applications.

\section{INTRODUCTION AND MOTIVATION}

\subsection{Motivation}

At present, there is a large amount of existing data, be it in the area of open data, which can generally be used free of charge, or in the area of official authority or commercial company data, the use of which is generally not free of charge or is subject to restrictions in use.

All these data are of high interest and value for citizens, administration and economy as well as for science, but are subject to different restrictions of use, costs and business models.

The handling of this extensive data collections is not yet practiced enough in teaching and research at German-speaking universities, although many, in particular spatially oriented courses of study with sometimes large numbers of students such as geography, spatial, urban or environmental planning, agriculture and forestry, geo or environmental sciences - could benefit enormously from this. This becomes particularly attractive if not only the data is provided, but also an application context from the respective subject is served.

This is where the project "Open Data for Teaching and Research in Spatial Study Programmes" (OpenGeoEdu) funded by the Federal Ministry of Transport and Digital Infrastructure (BMVI) in Germany comes in.

\subsection{Definitions}

Open Definition, a project of the Open Knowledge Foundation, sets out principles that define "openness" in relation to data and content ${ }^{1}$. "Open means anyone can freely access, use, modify, and share for any purpose (subject, at most, to requirements that preserve provenance and openness)." [...] "Open data and content can be freely used, modified, and shared by anyone for any purpose." (http://opendefinition.org). The prerequisites for this are public access and technical interoperability, the greatest possible freedom from costs and an open licence that allows extensive use. The openness of open data can be determined in the context of the 5-Star Open Data Model ${ }^{2}$.

Open data, whereby the focus in this project is on open geodata (Bill, 2018), is encountered in various places today (Figure 1):

- Open administrative data (government) from the European to the municipal level (e.g. INSPIRE, Govdata, mCLOUD, Geoportal.de, GeoSeaPortal.de, OpenData.HRO).

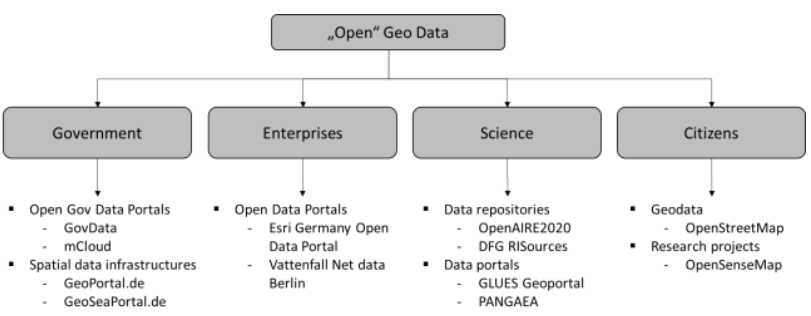

Figure 1. Four categories of "Open” Geodata.

- Open data from enterprises (e.g. Esri Germany Open Data Portal, utility data from Vattenfall).

- Open research data (science) with subject-specific data offers in disciplinary repositories (e.g. OpenAIRE2020, Pangaea).

\footnotetext{
${ }^{1}$ http://opendefinition.org

${ }^{2}$ https://5stardata.info/en/
} 
- Open data from the civil society (citizens) (such as OpenStreetMap, social media data or data from Volunteered Geographic Information or Citizen Science activities).

\section{OPENGEOEDU - THE PROJECT}

\subsection{Goal}

The OpenGeoEdu project intends to illustrate the use of open geodata in spatially oriented study courses using best-practice examples and, based on this, provides e-learning services for integration in a large number of study courses. The aim is to raise the open data treasure for science and to show manifold application and networking possibilities for research and teaching. The addressees are thus students, teachers and practitioners who can integrate the services of the OpenGeoEdu platform into their teaching, research or practical work, regardless of time and place, and can participate in the further development of the platform.

Thus, young academics (students in bachelor and master's degree courses and young researchers working on projects or doctoral theses) will learn to deal with open data as a matter of course and will thus experience significantly more attractive study and research conditions. The teaching staff at universities can integrate and further develop the case studies into their own course offerings. Furthermore, practitioners can refresh their GIS knowledge and discover the possibilities of open geodata.

\subsection{Participating institutions}

In order to create a broad offer for different spatially related study programmes four institutions from universities, nonuniversity research institutions and federal authorities with R\&D tasks from the area of responsibility of various federal ministries are involved.

- The Chair of Geodesy and Geoinformatics (GG) ${ }^{3}$ at the University of Rostock coordinates the project and creates and operates the platform. GG is introducing into Open activities and adds some general content on GIS, mapping, etc. GG is also implementing application examples in the field of environmental noise, landscape metrics and electro mobility.

- The research area "Monitoring of settlement and open space development" at the Leibniz Institute for Ecological and Regional Development (IÖR) ${ }^{4}$ has been operating the IÖR Monitor $^{5}$ for many years. Application examples for OpenGeoEdu address the topics of land use, existing buildings and transport infrastructure.

- $\quad$ The Federal Agency for Cartography and Geodesy $(\mathrm{BKG})^{6}$ is the most important provider of geodata at the national level in Germany. The Remote Sensing and Development Division in BKG contributes case studies on the European Earth Observation programme Copernicus and on geovisualisation.

- The Deutsches Biomasseforschungszentrum gGmbH $\left(\right.$ DBFZ $^{7}$ with its Bioenergy Systems Department focusses on application-oriented research in the field of sustainable bioenergy strategies. For OpenGeoEdu DBFZ provides practiceoriented case studies on the calculation of biomass potentials at different spatial levels.

3 https://www.auf.uni-rostock.de/professuren/a-g/geodaesieund-geoinformatik/

${ }^{4}$ https://www.ioer.de/1/home/

${ }^{5} \mathrm{http}: / / \mathrm{www}$.ioer-monitor.de/

${ }^{6} \mathrm{https} / / /$ www.bkg.bund.de/DE/Home/home.html

${ }^{7}$ https://www.dbfz.de/en/

\section{OPENGEOEDU - THE PLATFORM}

\subsection{OpenGeoEdu - the open online course}

\subsubsection{Technical issues}

The OpenGeoEdu platform provides - in the sense of Open Educational Resources (OER) - learning content freely accessible and uses open licenses. The platform can be accessed via the OpenGeoEdu website ${ }^{8}$. OpenGeoEdu is designed to be responsive, which means it can be used from a wide variety of devices (Figure 2).

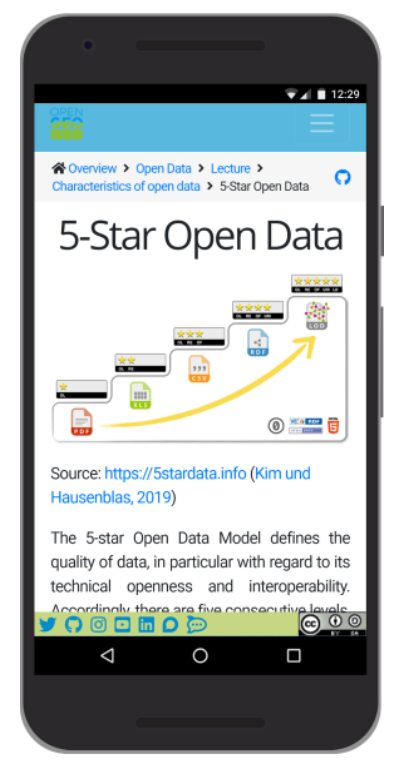

Figure 2. Smartphone user interface.

OpenGeoEdu combines a free offer of lecture units (implemented with GRAV 9 , a modern open source flat-file content management system, openly available at $\mathrm{GitHub}^{10}$ ). Tests and exercises are implemented in ILIAS ${ }^{11}$, an open source learning management system.

Users have to register if they want to earn credit points according to the European Credit Transfer System (ECTS) and receive certificates which can be recognised at their own universities. They can take tests on their state of knowledge and upload their processed documents. Each document is to be prepared in the sense of a scientific elaboration and, in addition to the scientific discussion, usually contains maps and diagrams of the results obtained for their respective research question.

\subsubsection{Course structure and content}

OpenGeoEdu offers its participants a wide variety of topics and learning materials. The course currently consists of eight lecture units (in Figure 3 on the left hand side the relevant chapters are numbered from 2. to 9.) and some additional material (an overview (Chapter 1.), specialized tutorials (10.) and a FAQ-part (11). All lecture units consist of a theoretical part (lectures and tests) and a practical part (exercises).

\footnotetext{
${ }^{8}$ https://www.opengeoedu.de/

${ }^{9} \mathrm{https}: / /$ getgrav.org/

${ }^{10}$ https://github.com/

${ }^{11} \mathrm{https} / / / \mathrm{www} . \mathrm{ilias} . \mathrm{de} /$
} 
In the theoretical part, basic knowledge, terms and methods are taught, which are necessary or helpful to understand the topic and to complete the exercises. In the practical part, the participants work on a current and practice-oriented question using GIS and open data. In Figure 3 on the right hand side the table of content of the lecture unit on Open Data is shown.

\begin{tabular}{l|c}
\hline 1. Overview & 3. Open Data \\
\hline Description Course parts & Lecture \\
Tools & Learning objectives an... \\
Data sheets & Backgrounds \\
Characteristics of o... & Interoperability \\
\hline 2. Open XX & 5-Star Open Data \\
3. Open Data & Open geodata \\
4. Electro mobility & Open Government Data \\
5. Environmental noise & Scientific data \\
6. Biomass Potentials & Enterprise \\
7. Landuse Monitoring & Volunteered geographi... \\
8. Remote Sensing & Literature \\
9. Geo-Information Systems & Exercise \\
10. Tutorials & Test \\
11. FAQ &
\end{tabular}

Figure 3. Course structure (overview and detail).

The online course is organized in two kinds of topics.

- The first kind consists of themes which are fundamental for all course parts. This includes an introduction to Open activities (2.) and Open Data (3.), a GIS crash course (9.) and some tutorials (10.).

- The second kind is a set of case studies on topics such as electro mobility (4.), environmental noise (5.), biomass potentials (6.), land use monitoring and landscape structure metrics (7.) as well as remote sensing (8.).

At the moment the user can choose from a total workload of 420 hours (equals 14 credit points according to the European Credit Transfer System ECTS). Lectures and tests account for 90 hours and exercises for 330 hours. Figure 4 illustrates the individual course parts with lecture and exercise times.

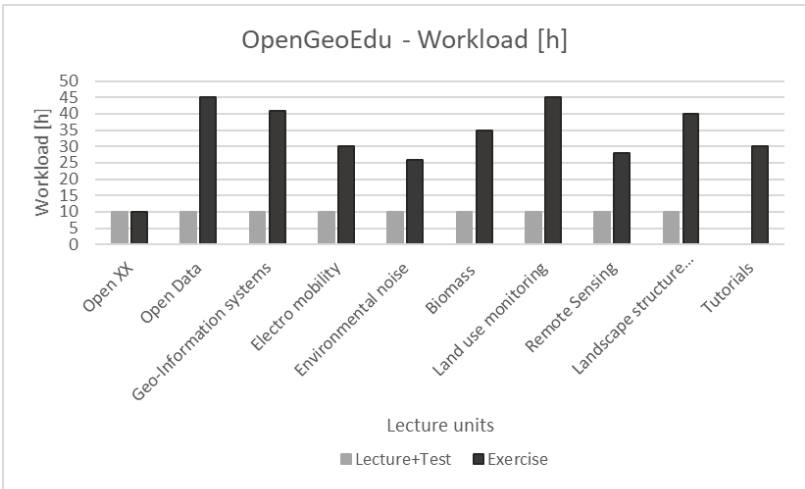

Figure 4. Workload distribution in OpenGeoEdu.

Content is presented through a wide variety of media forms such as videos, animations, images and scripts (Figure 5). Videos are presented in three forms: i) short teaser (1 to 2 minutes) to motivate for the specific lecture and exercise, ii) a video of approximately 15 minutes related to the lecture and iii) a video of ca. 15 minutes related to the exercise. In total more than 4.5 hours video material is available, in the platform as well as in our YouTube channel ${ }^{12}$.

\section{OpenGeoEdu Basics of}

\section{Open Data}

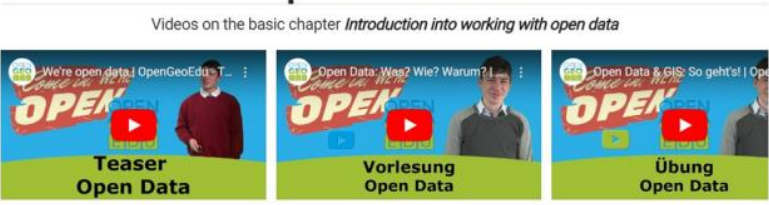

Figure 5. Video material examples (teaser, lecture and exercise).

\subsubsection{Course levels and ranges}

The material developed is intended to address issues on processing open data at different spatial ranges such as local/municipal, regional/national, European or even worldwide (Figure 6).

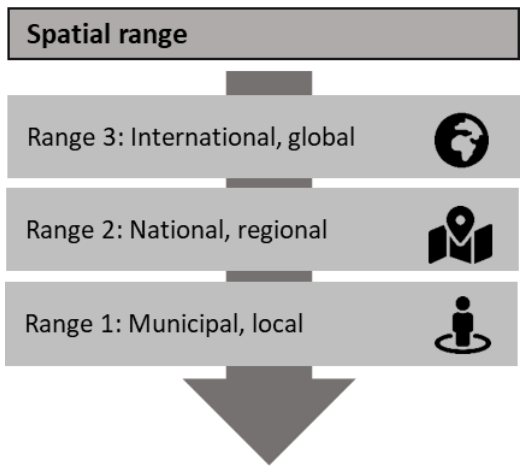

Figure 6. Spatial extents of exercises.

The learning contents are adapted to the heterogeneous previous knowledge of the users. We generally cover three different levels of difficulty (Advanced, Basic and Click-by-Click (ABClevels), Figure 7).

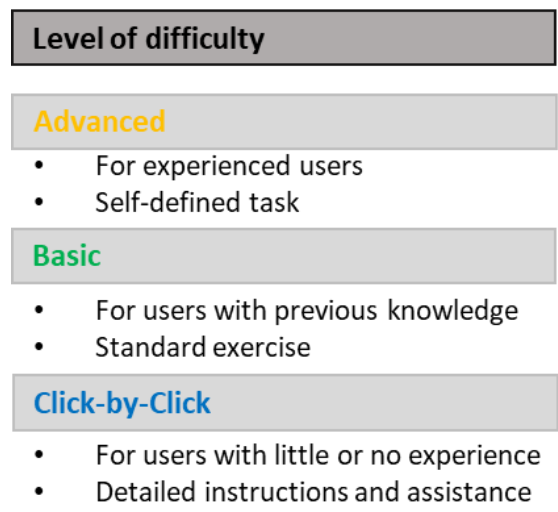

Figure 7. Levels of difficulty

- Basic is aimed at a user who is basically familiar with GIS and who can find an own solution with a rough framework of tasks, which he can adapt independently and creatively.

12 https://www.youtube.com/channel/UChFyYD9h3ynC1rXs3tyNdw 
- $\quad$ Advanced extends the basic level with own approaches like programming extensions, database queries, WebGIS technologies or special analysis and visualization ideas.

- Click-by-Click provides an extensive sequence of steps for the respective task, showing exactly how a solution can be achieved in the respective software. This enables even GIS novices to get started.

\subsubsection{Course modi}

The course can be started and used at all times wherever and whenever a participant is interested spending some time. Usually we announce the next course at the beginning of each half-year term and run it during the semester period. It can be included in teaching in different course modi:

- $\quad$ as a remote course for German speaking students and practitioners (parts of the course are also offered in English),

- as an inverted classroom and blended learning scenario in regular modules of bachelor's and master's programmes, i.e. on Environmental Engineering at Rostock University or

- in a project-based form in all kinds of further education study programmes.

\subsection{Case studies}

\subsubsection{Overview}

Using case studies from current and relevant topics in our society students and interested parties learn how to work with these data in practice. The concept of exploratory learning and the diverse solution possibilities allow individual answers and results to the various questions of our case studies in the course, which is presented here at a glance. The next subchapter then explains this in more detail using the electro mobility case study. We offer the following case studies:

- Environmental noise (GG) is a very interesting topic for many spatial study courses. The lecture briefly summarises essential aspects of noise, in the specific context of the EU Environmental Noise Directive. In the exercise, selected aspects of EU environmental noise mapping will be presented and processed with own data. Exercises are dealing with quiet areas in a municipality, rail noise in Germany and mobile noise mapping.

- The lecture Biomass potentials (DBFZ) offers basic knowledge, methods, data and examples for the determination of regional and national biomass potentials. The associated exercises encourage students to use open data and GIS to determine the possible contribution of biomass to the energy system in a defined region. Typical questions in the exercises are:

- What types of biomass are available in a certain region (e.g. cereal straw, biowaste)?

- Where are the resources located (e.g. on arable land, in settlement areas)?

- What quantities of biogenic resources can we use sustainably (e.g. considering soil fertility)?

- What contribution can biomass make to a specific part of the energy systems (e.g. transport sector)?

For further information on this case study see Kalcher \& Pfeiffer (2019).

- Land as a limited natural resource is dealt with in the Land Use Monitoring (IÖR) unit. A sustainable settlement development (i.e. low land consumption, greening of cities, avoidance of urban sprawl by prioritising inner development before outer) requires more accurate as well as small-scale information on spatial features such as land use, buildings and transport infrastructure. This thematic case study focuses on the fundamentals of data and analytics for supporting sustainable urban and spatial planning (Sikder et.al. 2019). The practical exercises available handle the following topic at local, regional and national level:

- Estimation of the land use share for the settlement and transport purpose (with open WebGIS services for example IÖR-Monitor and application of QGIS-environment).

- Computation of transport related land use indicator (using OpenStreetMap and authoratative data for a GIS project).

- Measuring and detecting changes in settlement and population density (with the Global Human Settlement Layer GHSL and ArcGIS online).

- Estimation of spatial patterns of building density in raster format (Fishnet Grid) (application of GeoDa and calculation of Univariate Moran's I (Global, Local)).

- Remote sensing (BKG) data also plays an important role. These data can be used in a variety of applications. The aim of the learning unit is to get to know the terminologies of optical remote sensing and to take a closer look at the properties of vegetation in this context. The importance of forests should be emphasized. There are several exercises available representing three areas with different spatial extensions:

- Local/municipal environment: Capture of windthrow areas.

- Regional/national environment: Recording of the tree population in large German cities.

- European/international environment: Urban green and changes in land cover/use of European capitals.

\subsubsection{Electro mobility in detail}

Electro mobility is a very topical issue overall and the emerging industry shows clear development potential. The lecture deals fundamentally with the topic of electro mobility and presents the current situation e.g. regarding the charging station infrastructure as well as obstacles in the increase of the number of electric cars.

For a practice-oriented teaching, the open online course uses freely available data from official sources or open administrative data as well as user-generated open data.

The case study of electro mobility (GG) should be used to illustrate briefly the problems, technologies used and levels. For this topic, current tasks are offered on three spatial extents:

- Local/municipal: The user should explore the local charging station situation around his place of residence. ArcGIS online is used as a platform. For this purpose the user selects open data of the charging stations as well as the street data in ArcGIS online. Different GIS accessibility analyses (linear distance, road network) are carried out and visualized.

- National: Here the user is to investigate connections between the charging station network and demographic data (potential buyers). QGIS is used in the case study. In addition to the charging stations, demographic data from the Federal Statistical Office are analysed, which are linked to the administrative area boundaries of the BKG. Factors such as reach, income and age are evaluated multivariately. 
- $\quad$ Europe-wide: Here the user has to plan a journey across Europe, whereby the routing service of OSM is coupled with further processing in QGIS.

In this half-year term a student analysed a journey from Tübingen to Rome using an electric car with a much smaller range than a vehicle with a combustion engine (Figure 8). In addition he analysed the street types used and the slopes on this journey using Open Street Map and a terrain model (Figure 9).

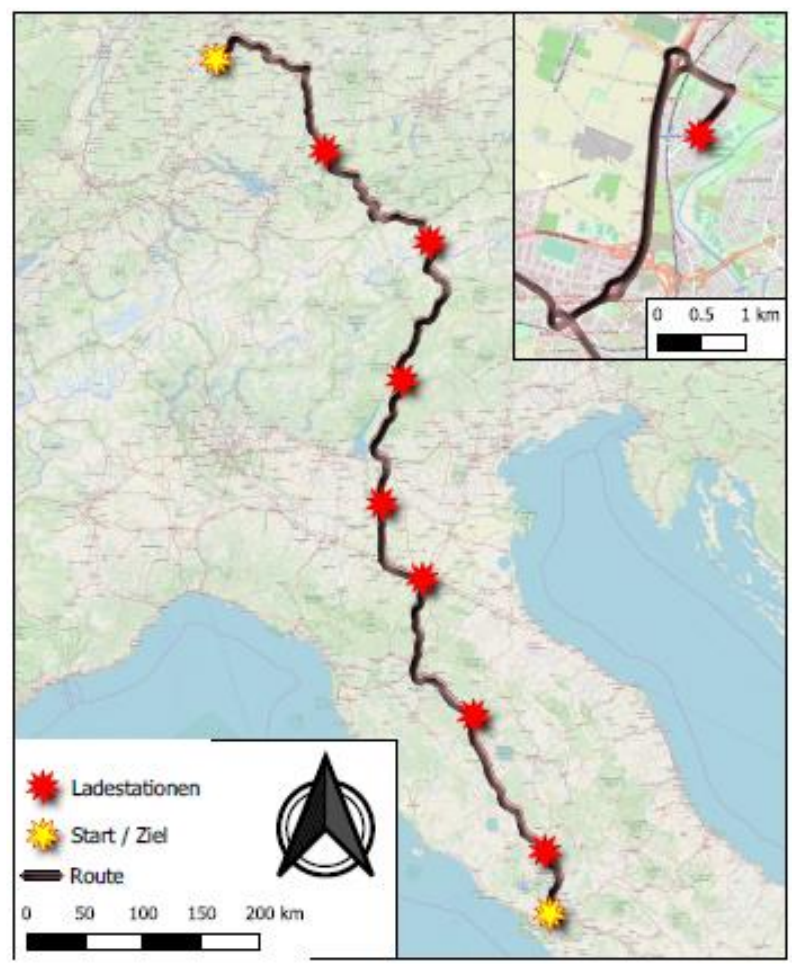

Figure 8. A journey from Tübingen to Rome with an e-car (red charging stations, yellow - start and end point).

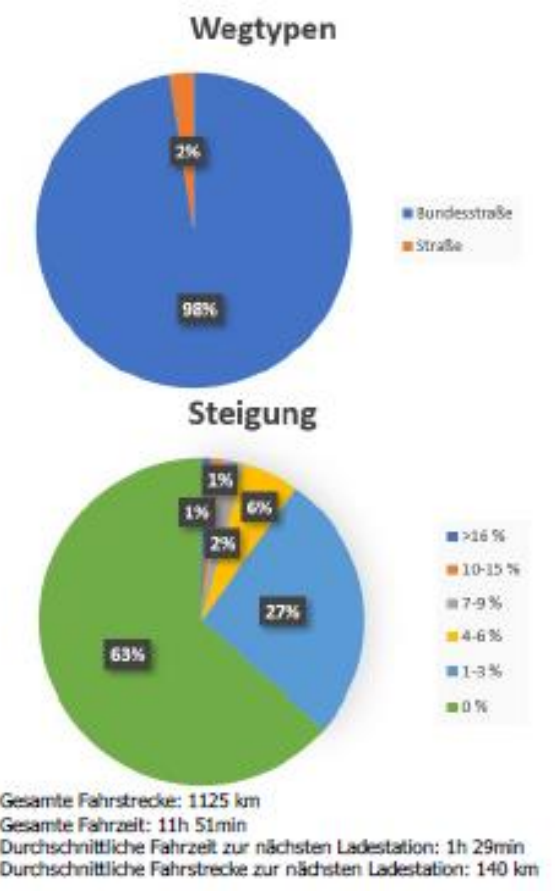

Figure 9. Street types and slopes on this journey.

\section{OPENGEOEDU - THE OPEN DATA PORTAL}

The OpenGeoEdu data portal ${ }^{13}$ maintains an extensive and upto-date list of available catalogues and data portals, which is designed in such a way that each entry is provided with a set of uniform descriptions and can be selected using filter criteria. The architecture of the portal is described in Hinz/Bill, $2018 \mathrm{a} / \mathrm{b}^{14}$.

The portal combines a tabular view with a WebGIS frontend (Figure 10) that allows a spatial exploration as well as filtering by spatial extent (bounding box), category, portal range, and text search.

The data portals are categorized either as open data portals in its narrower sense (according to the definition in chapter 1.2) or by the specific domain of the information, i.e. scientific-, environmental-, geographical- or statistical data. Citizen Scienceprojects are separated as another category.

Each portal is represented by a marker on the map. The shape of the marker symbol differentiates between the various categories of portal types (Figure 11). As portals also vary in the spatial range for which they provide data, e.g. for a single city or commune (communal), for regions and federal states (regional), or for country-level data (national/international), these ranges are illustrated by different colours of the markers (Fig. 12). A marker-based representation of data portals was favoured over polygons because the regions covered by the portals are highly irregular. They frequently overlap, often cover a set of collaborating regions, and sometimes do not match with any administrative divisions (e.g. cross-boundary regions, river sections or natural landscapes). The markers are positioned inside these fuzzy regions, preferably at the publisher's location.

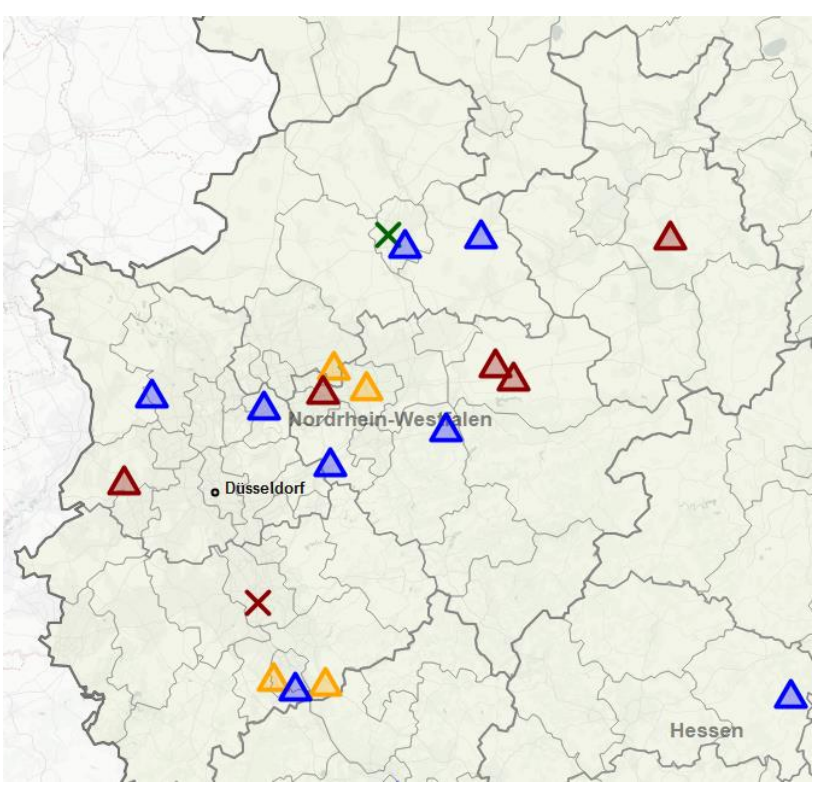

Figure 10. WebGIS interface of the data portal with a customized view of North Rhine-Westphalia including geoportals / GDIs and citizen science projects only.

\footnotetext{
${ }^{13}$ https://portal.opengeoedu.de/

14 https://agile-online.org/conference/proceedings/proceedings-
} 2018 


\begin{tabular}{|l|l|}
\hline \multicolumn{2}{|l|}{ Symbol representing the portal type } \\
\hline & Open Data Portal \\
\hline & GDI/ Geoportal \\
\hline & Statistical Data Portal \\
\hline$\square$ & Environmental Data Portal \\
\hline+ & Research Data Portal \\
\hline$X$ & Citizen Science Project \\
\hline
\end{tabular}

Figure 11. Symbols for different portal types

\begin{tabular}{|c|c|}
\hline \multicolumn{2}{|c|}{ Colour representing the extent } \\
\hline (green) & international \\
\hline (orange) & national \\
\hline (blue) & regional \\
\hline (red) & communal \\
\hline
\end{tabular}

Figure 12. Colours illustrating the range of the portal.

Comparable overviews already exist at international level. For example, OpenDataSoft has created the expandable web map Open Data Inception ${ }^{15}$ with more than 3,800 Open Data Portals worldwide. The non-profit organization CTIC provides a similar platform with the Public Dataset Catalogs Facets Brow$\operatorname{ser}^{16}$, which is based on the principles of Linked Open Data (LOD) and Semantic Web Technologies (CTIC-CT). These projects are much more ambitious in terms of the amount of data to be collected, but would require a worldwide, active user community or intensive administrative support to keep them consistently complete, detailed and up-to-date. The Open Data Atlas made by Thomas Tursics ${ }^{17}$ features a web map of 111 open data portals within the DACH-Region (FRG: 86, AU: 19, $\mathrm{CH}: 6$ ). The herein described portal, in contrast, provides a more extensive overview that is more open in terms of portal categories.

In addition to obvious open data sources, the portal in OpenGeoEdu also lists platforms where open data is not always presumed, including spatial data infrastructures (GDI) and geoportals and open data offers from companies. Although these are often subject to usage restrictions or must be purchased commercially, there is a tendency towards open data or free of charge offers, such as Web Map Services (WMS) to be used as background maps. In addition, research data, statistical, and environmental portals have been integrated. In April 2020 , more than 370 portal pages are available for the DACH region (FRG: 229, AU: 47, CH: 85, Others: 12, see Figure 13).

Since OpenGeoEdu is promoted at various DACH universities, there is also the potential of a growing user community, which can update and complement this portal. On a technical level, this is made possible by a web form, which can be used to create new entries or to request the correction and completion of existing entries.

\footnotetext{
${ }^{15} \mathrm{https}$ ://opendatainception.io/

${ }^{16} \mathrm{http}: / /$ datos.fundacionctic.org/sandbox/catalog/faceted/

${ }^{17} \mathrm{http}: / /$ opendata.tursics.de
}

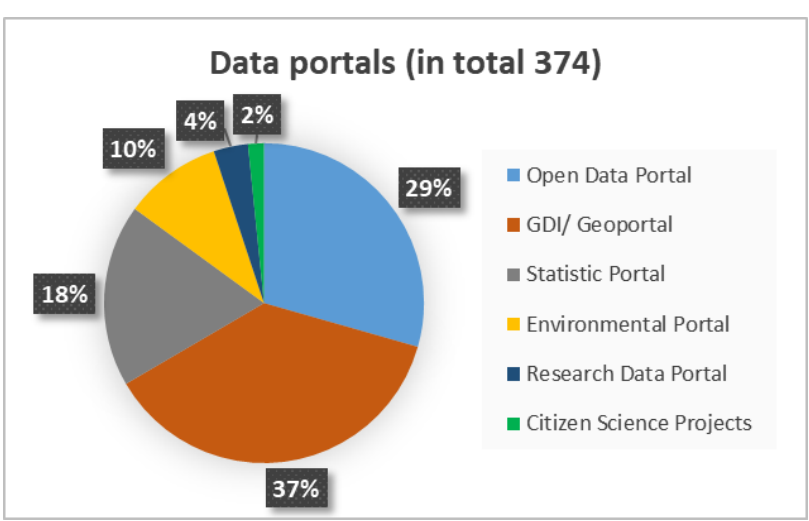

Figure 13. Data portals in OpenGeoEdu's OpenDataPortal (Status April 2020).

\section{OPENGEOEDU - EXPERIENCES}

OpenGeoEdu is promoted through a variety of channels - from the classic newsletter, trade fair presentations and congress workshops to social media such as Twitter ${ }^{18}$, YouTube etc.

\subsection{Learning objectives, scope and implementation}

In order to ensure compatibility in bachelor's and master's programmes - according to the Bologna rules, and thus the recognition of the workload and grades achieved in the course at universities in the DACH region - the module "Open Geodata" is a regular component of an accredited university course at the University of Rostock. The module description states the following as learning and qualification objectives in the master's programme in Environmental Engineering: "Students learn how to handle open geodata and acquire the ability to work on case studies on various current and socially relevant issues. The students learn to work on the case studies independently and creatively and to present their results in a scientific paper".

In total, a maximum of 14 credit points (420 hours workload) can be achieved, the smallest certified unit is half a credit point, which corresponds to 15 hours of workload. As examination achievements, online tests are to be taken and written evidence is to be prepared, which usually contains thematic maps and diagrams as proof of the GIS processing of a problem.

In the winter semester 2018/2019 the open online course Open GeoEdu took place for the first time. In April 2020 the online course has started for the fifth time. Parallel to the open course for everyone, parts of the course were also conducted in the attendance courses in Environmental Engineering Sciences at the University of Rostock in order to receive direct feedback from students. The GIS case study "Sustainable Development Goals", the sustainability goals of the United Nations, was dealt with students, both from a bachelor (between 30 and 60 students) and master (between 15 and 25) programme, each of them in the first semester.

In addition, experiments were conducted with master students in the sense of an "Inverted Classroom" or "Flipped Classroom", a teaching method in which the roles of teacher and student are reversed ("reversed teaching"). The students acquire the content provided by the teachers in digital form

\footnotetext{
${ }^{18} \mathrm{https} / / /$ twitter.com/opengeoedu
} 
independently, usually at home using our learning units in OpenGeoEdu. The face-to-face sessions are then used to consolidate what has been learned. The content - in this course part we tested the units "Open Activities" and "Open Data" - is then deepened and the students' own creativity is encouraged by a problem with open geodata, which can be worked on independently by each student.

\subsection{Selected results}

The evaluation statistics (Figure 14) since the start of the course in October 2018 show that until spring 2020, more than 300 participants had dealt with course content, a good 250 of whom also took online tests. Registered users first complete a knowledge test of 20 questions in 20 minutes for each part of the course after finishing the lecture part. The tests seem to be a first hurdle at which interested users fail. The number of those who have actually independently processed and submitted document tasks with open data is then quite low at just around 60 (plus some 50 Rostock students finishing their tasks, but not using ILIAS for registering). Still the majority of the course participants are students from Rostock. The number of other students who are not enrolled in Rostock (e.g. students from Cologne, Bonn, Nürtingen, Tübingen, Greifswald etc.) and who completed parts of the course lies under 20 . The highest number of credit points for external students was three, i.e. 90 hours workload.

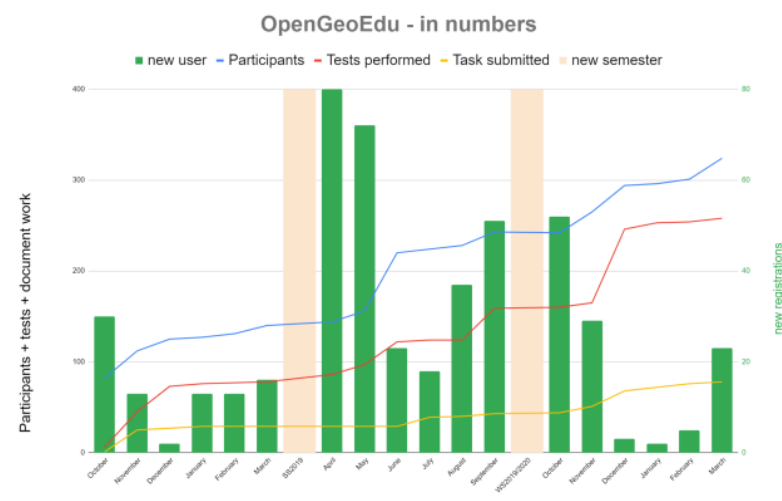

Figure 14. User statistics (October 2018 til March 2020)

Students from Rostock University all had to deal with the topic "Sustainable Development Goals". The data is from the United Nations and can be downloaded for free. Each student had to select an own sustainability indicator and produce both a chronological evaluation in diagram form and as a thematic map. The master students also had to explore the topic of openness/open data independently in the sense of the inverted classroom and then work on a freely chosen topic with open data. This resulted in many creative and informative scientific elaborations, e.g. on the topics "Potential of quiet areas in Rostock with regard to noise protection and population density", "Total energy production and consumption by federal states", "Modelling of the periods of assistance in emergency rescue in the rescue service areas of Rostock" (Figure 15) as well as numerous accessibility analyses of supermarkets/ pharmacies/physician's or offices/sports halls in Rostock.

Figure 16 shows a thematic map on electro mobility with respect to population density (left) and income (right).

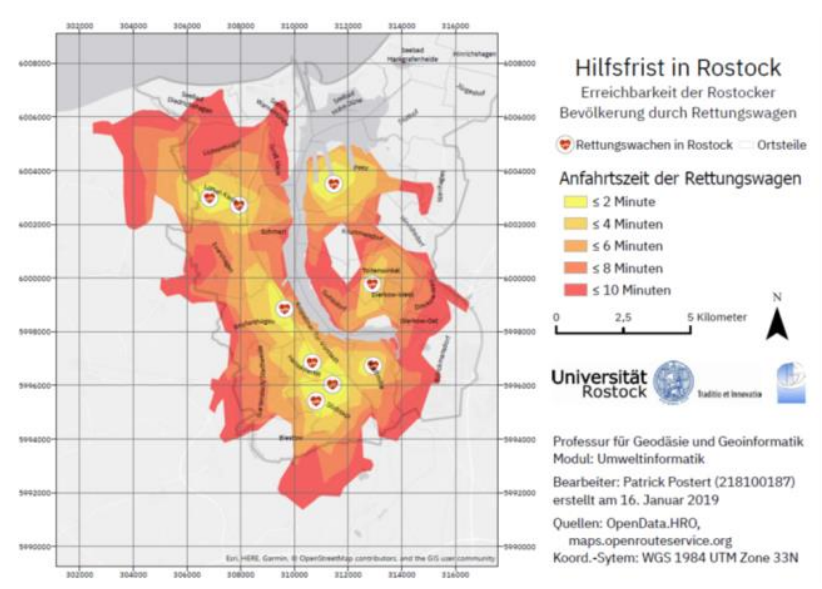

Figure 15 . Reachability by rescue services in Rostock, Germany.

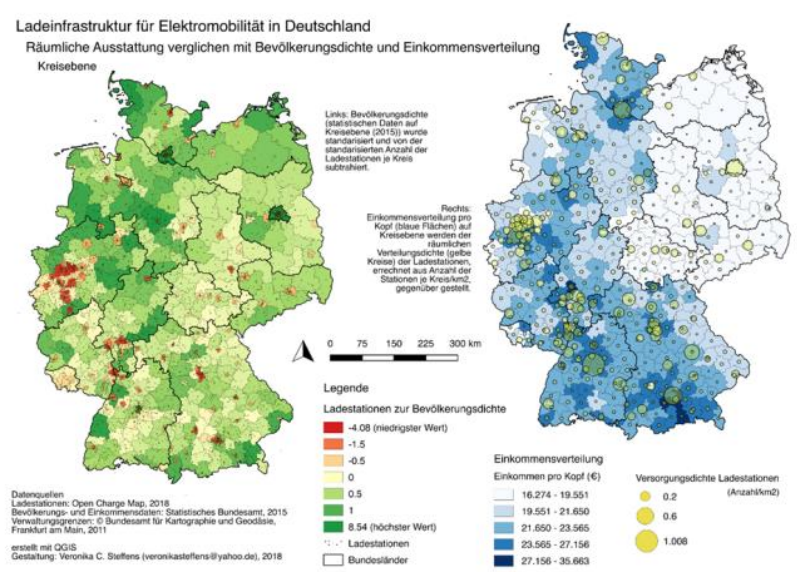

Figure 16. Thematic map on electric mobility situation in Germany.

\subsection{Lessons learned}

The integration of the course into bachelor's and master's programmes at Rostock University as well as the usage of external users from German speaking countries gave many hints to improve the course. Based on the feedback from teachers and students, the course offerings were revised each semester and new course contents were being created. This approach is maintained, so that the course is constantly being improved.

Since the first OpenGeoEdu course in winter term 2018/2019 the following points have been identified as particularly important:

- A high quality didactic preparation is necessary in order to make the course more attractive and understandable. This point was countered by an increased use of multimedia and interactive contents (especially videos and graphics, reduction of text parts) and the testing of differrent video formats. In future this target group-oriented preparation of the content will be further expanded.

- The online communication services provided (e.g. chat, consultation hours, commentary function) were almost not used. In the future, students are to be reached via different channels and encouraged to actively participate and communicate via the learning platform (e.g. through newsletters, events/workshops, creative content related to cur- 
rent world topics). This also includes a systematic gathering of feedback from students and teachers.

- Registration prevents potential users from using the course contents. In the first OpenGeoEdu course, registration was required to complete tests and to upload exercises. We identified this registration as the first hurdle, which has been lowered in the meantime: In addition to the lectures, all exercise parts are now completely open. Registration is only necessary when users submit their documents in order to receive certificates.

- The online tests turn out to be the next obstacle. After failing, the participants will probably find the level too high and leave the course.

- The course offerings have all been revised each semester and new course content is being created.

\section{CONCLUSIONS}

OpenGeoEdu is an open learning platform on the topic of open (geo)data. It offers comprehensive knowledge in the context of the Open Science and Open Data movement as well as real case studies that are suitable for many spatially oriented study programmes. Thus OpenGeoEdu promotes the independency and creativity of students through exploratory learning. It enables teachers to participate and expand the platform by adding their own case studies or by integrating them into their own teaching.

A more comprehensive description of the project, the platform and the portal can be found in Bill/Lorenzen-Zabel/Hinz (2018, 2019).

OpenGeoEdu supports learning in all situations with its open online learning platform for everyone:

- Students in bachelor's and master's degree programmes can acquire credit points in OpenGeoEdu, which can be credited to their courses of study at their university.

- Teachers can integrate OpenGeoEdu into their course offerings or contribute their own examples and make them available to others.

- Practitioners can use OpenGeoEdu to gain practical experience with GIS and open data.

\section{ACKNOWLEDGEMENT}

The authors would like to thank the Federal Ministry of Transport and Digital Infrastructure (BMVI) for funding under the mFUND programme (FKZ: 19F2007A). The project itself, funded by the BMVI as part of the mFUND programme, will run until mid-2020.

\section{REFERENCES}

Aberle, H., Hovenbitzer, M. (2019): (E-)Lernen mit offenen Geo- und Fernerkundungsdaten. In: AGIT Journal für Angewandte Geoinformatik. 5-2019, Vol. 5, Pages 116-124. doi:10.14627/537669010.

Bill, R. (2018): Offene Geodaten - ein Paradigmenwechsel. In: Harzer, C. (Hrsg.): GIS-Report: Software - Daten - Firmen. 2018/2019. Karlsruhe: Harzer Verlag. Pages 9 - 15.

Bill, R., Lorenzen-Zabel, A., Hinz, M. (2018): Offene Daten für Lehre und Forschung in raumbezogenen Studiengängen OpenGeoEdu. gis.science. Vol. 1, Pages 32 - 44.

Bill, R., Lorenzen-Zabel, A., Hinz, M. (2019): Lernen mit offenen Geodaten. In: Bill, R., Zehner, M.L.: GeoForum MV 2019 - Geoinformation in allen Lebenslagen. Berlin: GITO mbH. Pages 123 - 129.
Hinz, M., Bill, R. (2018a): Ein zentraler Einstiegspunkt für die Suche nach offenen Geodaten im deutschsprachigen Raum. In: AGIT Journal für Angewandte Geoinformatik. 4-2018, Vol. 4, Pages 298 - 307. doi.org/10.14627/537647038.

Hinz, M., Bill, R. (2018b): Mapping the landscape of Open Geodata. In: Mansourian, A., Pilesjö, P., Harrie, L., von Lammeren, R. (Eds.): Geospatial Technologies for All: short papers, posters and poster abstracts of the 21th AGILE Conference on Geographic Information Science. Lund University 12-15 June 2018. Lund, Sweden.

Kalcher, J., Pfeiffer, A. (2019): Von offenen Daten zur Karte. Berechnung und Darstellung von räumlich hochaufgelösten Biomassepotenzialen. In: Nelles, M. (Hg.): 13. Rostocker Bioenergieforum. Rostock Univ., Schriftenreihe Umweltingenieurwesen, Vol. 87, Page 45-51.

Sikder, S.K., Herold, H., Meinel, G., Lorenzen-Zabel, A., Bill, R. (2019): Blessings of Open Data and Technology: E-Learning Examples on Land Use Monitoring and E-Mobility. Getzinger, G., Jahrbacher, M. (Eds.): Conference Proceedings of the STS Conference Graz 2019: Critical lssues in Science, Technology, and Society Studies. Technical University Graz. doi: 10.3217/978-3-85125-668-0. Pages 402 - 414. 